Jpn. J. Med. Sci. Biol., 43, 183 - 195, 1990.

\title{
INCIDENCE OF CLOSTRIDIUM BOTULINUM IN HONEY OF VARIOUS ORIGINS
}

\author{
Hiroyuki NAKANO, Tadashi OKABE, Hideo HASHIMOTO \\ and Genji SAKAGUCHI 1
}

Department of Food Microbiology and Hygiene, Hiroshima University, Kagamiyama, Higashi-Hiroshima, Hiroshima 724 and 1College of Agriculture, University of Osaka Prefecture, 804 Mozu-ume-machi 4-chome, Sakai, Osaka 591

(Received September 17, 1990. Accepted November 1, 1990)

SUMMARY: By the dilution-centrifugation method, 270 honey samples, both domestic and imported, were examined and Clostridium botulinum was detected in 23 samples (8.5\%); type $\mathrm{A}$ in 11 samples, type $\mathrm{B}$ in two, type $\mathrm{C}$ in 10 , and type $\mathrm{F}$ in one. Of 58 domestic honey samples, six $(10 \%)$ were positive; three gave type $\mathrm{A}$ and the other two type C. Among imported honey samples, Chinese honey gave $12 \%$ positives (types A, B, and C) and Argentina honey $20 \%$ positives (types A and F). The incidence was higher with samples taken from drums (18\%) and from apiaries $(23 \%)$ than marketing honey (5\%). It was estimated that most positive samples contained spores in one per gram or lower concentrations. One sample contained 4 type A spores per gram and another $36-60$ type $F$ spores per gram. No distinct biochemical properties were found with the honey isolates.

\section{INTRODUC'TION}

Infant botulism was first reported in the United States in $1976(1,2)$. Only infants aged between 3 weeks and 8 months develop the symptoms after ingestion of Clostridium botulinum spores which may germinate, proliferate and produce

中野宏幸·岡部忠史·橋本秀夫 (広島大学生物生産学部 東広島市鏡山)

阪口玄二 (大阪府立大学農学部 堺市百舌鳥梅町) 
the toxin in the intestines $(3,4)$. More than 650 cases were reported from 1976 to 1986 in the United States and also in other countries in North and South America, Europe, Australia and Asia (Arnon, S. S., personal communication). The causative organisms were principally of types A and B; C. barati producing type $\mathrm{F}$ botulinum toxin (5) was involved in a case and $C$. butyricum producing type $\mathrm{E}$ toxin (6) in two cases. The source of infection so far identified is honey. $C$. botulinum spores have been detected in honey at certain percentages (7-9), and a warning was issued in the United States not to feed honey to infants under 12 months of age.

In Japan, the first case of infant botulism associated with honey, was diagnosed in 1986 (10). The Ministry of Health and Welfare organized a study group to examine honey for contamination with C. botulinum (11). A total of 512 samples of domestic and imported honey were examined by the group and $C$. botulinum was detected in 27 samples (5.3\%) (11).

The present communication describes the results of the surveys conducted during the period from 1986 to 1990 of 270 honey samples, including those collected by the Ministry of Health and Welfare in 1986 and examined by us. Attempts were made to correlate the incidence to the country of origin, the processing of honey or the storage period, and to characterize the isolates. 'The procedures we used for detection of $C$. botulinum in honey were evaluated by adding known numbers of $C$. botulinum spores to a honey sample.

\section{MA'TERIALS AND METHODS}

Honey samples: A total of 270 samples included 90 purchased at shops in Osaka in 1986 and 1987, 50 taken from drums soon after import, 13 taken directly from bee combs at apiaries in Osaka, and 117 purchased at shops in Hiroshima during the period from 1988 to 1990 . These samples included 58 domestic, 177 imported, 10 mixtures of domestic and imported, and 25 of unknown origin. The imports were from China (76 samples), Argentina (15), Hungary (12), USA (10), Canada (5), USSR (4), Australia (3), New Zealand (3), France (2), Spain (2), Mexico (2), and UK (1). The nectar sources were acacia, clover, orange, Chinese milk vetch.

Procedures for detection of $\mathrm{C}$. botulinum in honey: The dilutioncentrifugation method of Midura et al. (8) was followed, with slight modifications. Honey samples were warmed to $37 \mathrm{C}$ (solidified ones to 52 to $53 \mathrm{C}$ ), and a $20 \mathrm{-g}$ portion was taken from each and diluted with 100 to $150 \mathrm{ml}$ of sterile distilled 
water. The mixture was shaken and centrifuged at 8,000 to $10,000 \times \mathrm{g}$ for $30 \mathrm{~min}$ at $20 \mathrm{C}$. A small amount of distilled water was added to the precipitate to make a suspension of about $2 \mathrm{ml}$. Four tubes of $10 \mathrm{ml}$ of cooked meat medium (Difco) supplemented with $0.1 \%$ glucose and $0.2 \%$ soluble starch were inoculated; two with $0.9 \mathrm{ml}$ of the undiluted suspension and the other two with $1 \mathrm{ml}$ of a 10 -fold diution. One set of tubes were heated at $80 \mathrm{C}$ for $15 \mathrm{~min}$, and the other untreated. All tubes were incubated in anaerobical jars at $30 \mathrm{C}$ for 7 days. A 5-fold dilution of the centrifugal supernatant of each culture was injected intraperitoneally into a mouse, which was observed for 4 days. When the mouse developed symptoms and died, the toxin was typed with type-specific antitoxins (Chiba Serum Institute, Ichikawa, Chiba). For some samples, the suspension of the centrifugal precipitate of a $20-\mathrm{g}$ sample was inoculated into only two tubes of cooked meat medium. For the 80 samples collected in 1988, distilled water with and without added $0.5 \% \mathrm{CaCO}_{3}$ was used to dilute the honey. Enrichment culture was repeated twice or three times with the 60 samples collected in 1986.

Viable counting of $\mathrm{C}$. botulinum: When all four tubes gave positive results, viable counting of $C$. botulinum was attempted by three different procedures. As a direct plating method, $0.2 \mathrm{ml}$ of a twofold dilution of the honey sample was plated on 5\% egg yolk GAM agar (Nissui Pharmaceutical Co., Tokyo) supplemented with $0.1 \%$ cysteine and also on CBI agar plates when type A, B, or $\mathrm{F}$ toxin was detected. Colonies with pearly layers were counted. Besides, 10 -fold serial dilutions of the twofold dilution were each inoculated in 1-ml amounts into three tubes of cooked meat medium, which were incubated and tested for the toxicity by mouse ip injection to calculate the most probable number (MPN) of $C$. botulinum. Furthermore, a diluted sample was filtered through HGMF (Hydrophobic grid membrane filter, QA Company., Toronto, Canada), which was cultured on the surface of a GAM agar plate with nitrocellulose membrane underneath the HGMF. Botulinum toxin blotted to the nitrocellulose membrane was detected by ELISA (13).

Isolation of $\mathrm{C}$. botulinum: The toxic cultures in cooked meat medium were plated on 5\% egg yolk GAM agar plates and, when proteolytic group I organisms (14) were suspected from the toxin type detected, on CBI agar plates. The plates were incubated anaerobically for 3 days at $30 \mathrm{C}$. Such colonies that were surrounded with pearly layers were picked up into tubes of cooked meat medium to test for the toxin production. When colony isolation from agar plates was difficult, the HGMF-ELISA method was applied prior to plating.

Biochemical tests of the isolates: The isolates were tested for some biochemical properties. Gram staining was performed by the modified method of Hucker; spore staining was made by the method of Schaeffer-Fulton on 7 day cultures in cooked meat medium. Aerobic culture, tests for lipase and lecithinase were made with 5\% egg yolk GAM agar plates; hemolysis was tested on sheep blood agar (BBL) plates. Digestion of meat was tested in cooked meat medium by incubation at $30 \mathrm{C}$ for 2 weeks. Carbohydrate fermentation was tested in GAM 
semisolid base (Nissui Pharmaceutical Co.) with each carbohydrate added in $1 \%$. In 2 and 5 days at $30 \mathrm{C}$, the BTB-MR indicator was added to compare the color with that of the carbohydrate-free culture. Motility was tested in the same medium. Growth was tested also on CBI agar plates containing cycloserine, sulfamethoxazole and trimethoprim. Nitrate reduction was tested in GAM semisolid medium containing $0.1 \%$ glucose and $0.3 \% \mathrm{KNO}_{3}$ in 2 days of incubation.

Evaluation of the procedure for detection of $\mathrm{C}$. botulinum in honey: A spore suspension of $C$. botulinum type A strain 62 was so diluted that the dilutions would contain $100,10,5,3,1$, and 0.5 spores $/ \mathrm{ml}$. Each dilution in $1.0-\mathrm{ml}$ amounts was inoculated into a $10 \mathrm{~g}$ honey sample and three tubes of cooked meat medium. The inoculated honey was subjected to the above-described dilutioncentrifugation method. In these tests, diluent with and without added $0.05 \%$ $\mathrm{CaCO}_{3}$ was used. The experiment was repeated twice.

\section{RESULTS}

Detection of C. botulinum in Honey Samples

Of 270 honey samples, 23 (8.5\%) were shown to contain C. botulinum (Table I). The toxin types found were type $A$ in 11 samples, type $B$ in two samples, type $\mathrm{C}$ in 10 samples, type $\mathrm{F}$ in one sample, and both types $\mathrm{A}$ and $\mathrm{C}$ in one sample. The incidences were $5 \%(11 / 207)$ in bottled samples from shops, $19 \%$ in 50 samples taken directly from drums, and $23 \%(3 / 13)$ in samples taken from apiaries. 'The incidence of $C$. botulinum in imported honey was $9.6 \%(17 / 177)$, while that in domestic honey $10.3 \%$ (6/58) (Table II). Among marketing honey samples, the incidence was $6.3 \%(8 / 127)$ in imported honey, while $6.7 \%(3 / 45)$ in domestic samples. As shown in Table II, incidences by country of origin were 9/76 (12\%) of China origin, and 3/15 (20\%) of Argentina origin. Samples from Hungary, Spain, and Mexico each gave one positive only. The toxin types found were types A, B and $\mathrm{C}$ in Chinese honey, types $\mathrm{A}$ and $\mathrm{F}$ in Argentina honey and type $\mathrm{A}$ in Japanese honey. With regard to bottled honey samples collected from shops, the incidences were $7 / 90(7.8 \%)$ and $4 / 117(3.4 \%)$ for samples collected in 1986-87 and 1988-90, respectively. 
Table I. Honey samples tested for C. botulinum in 1986-1990

\begin{tabular}{lccl}
\hline $\begin{array}{l}\text { Sample } \\
\text { source }\end{array}$ & $\begin{array}{l}\text { Number of } \\
\text { samples } \\
\text { tested }\end{array}$ & $\begin{array}{l}\text { Number of } \\
\text { positive (\%) }\end{array}$ & \multicolumn{1}{c}{ Toxin types 1} \\
\hline Bottle & 207 & $11(5.3)$ & $\mathrm{A}(5), \mathrm{C}(5), \mathrm{F}(1)$ \\
Drum & 50 & $9(18.0)$ & $\mathrm{A}(3), \mathrm{B}(2), \mathrm{C}(3), \mathrm{A}+\mathrm{C}(1)$ \\
Apiary & 13 & $3(23.1)$ & $\mathrm{A}(2), \mathrm{C}(1)$ \\
Total & 270 & $23(8.5)$ & $\mathrm{A}(10), \mathrm{B}(2), \mathrm{C}(9), \mathrm{F}(1), \mathrm{A}+\mathrm{C}(1)$ \\
\hline
\end{tabular}

1The figures in parentheses show the numbers of samples positive for C. botulinum of the type.

Table II. Country of origin of honey samples tested for C. botulinum

\begin{tabular}{lclllll}
\hline \multirow{2}{*}{$\begin{array}{l}\text { Country } \\
\text { of origin }\end{array}$} & $\begin{array}{l}\text { Number } \\
\text { of } \\
\text { samples }\end{array}$ & Number of & & \multicolumn{4}{c}{ Toxin type } \\
\cline { 5 - 7 } positive (\%) & A & B & C & D \\
\hline China & 76 & $9(11.8)$ & 3 & 2 & 4 & 0 \\
Japan & 58 & $6(10.0)$ & 3 & 0 & 3 & 0 \\
Argentina & 15 & $3(20.0)$ & 2 & 0 & 0 & 1 \\
Hungary & 12 & $1(8.3)$ & $1 *$ & 0 & $1^{*}$ & 0 \\
Spain & 2 & $1(50.0)$ & 1 & 0 & 0 & 0 \\
Mexico & 2 & $1(50.0)$ & 0 & 0 & 1 & 0 \\
USA & 10 & 0 & 0 & 0 & 0 & 0 \\
Others & 18 & 0 & 0 & 0 & 0 & 0 \\
Unknown(foreign) & 31 & $2(6.5)$ & 1 & 0 & 1 & 0 \\
Mixture(foreign) & 11 & 0 & 0 & 0 & 0 & 0 \\
Mixture(foreign+Japan) & 10 & 0 & 0 & 0 & 0 & 0 \\
Unknown & 25 & 0 & 0 & 0 & 0 & 0 \\
Total & 270 & $23(8.5)$ & 11 & 2 & 10 & 1 \\
\hline
\end{tabular}

*One sample contained two types of C. botulinum spores. 


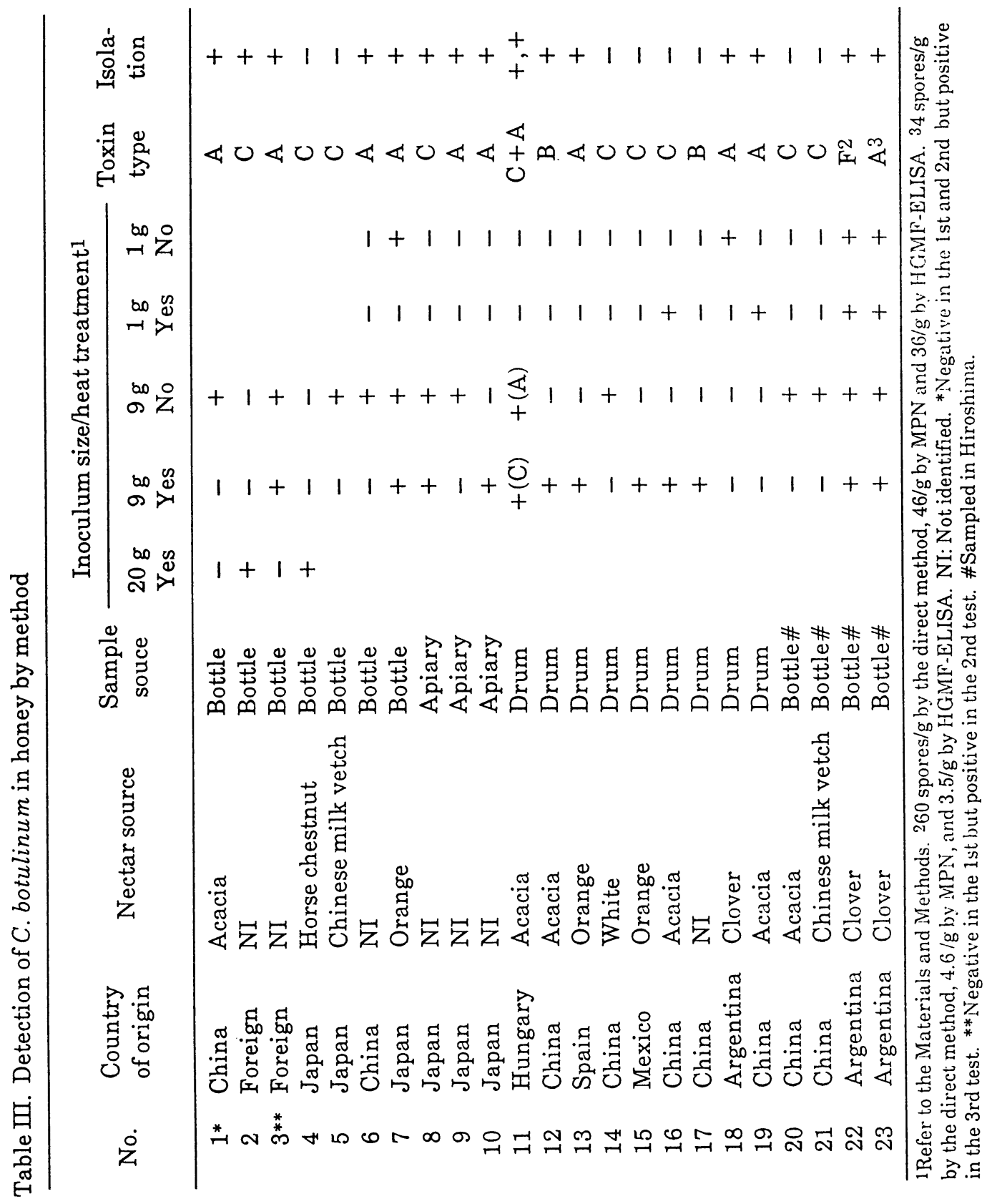


The Relation between the Positivity and the Procedure of Detection

Table III shows the results of detection of C. botulinum from honey samples with the country of origin, nectar source, sample source and the methods of detection. No correlation was seen between the toxin type and heat treatment or

Table IV. Biochemical properties of the C. botulinum isolates from honey

\begin{tabular}{|c|c|c|c|c|}
\hline Toxin type & A & $\mathrm{B}$ & $\mathrm{C}$ & $\mathrm{F}$ \\
\hline Positive samples & 11 & 2 & 10 & 1 \\
\hline Number of isolates & 11 & 1 & 3 & 1 \\
\hline \multicolumn{5}{|l|}{ Test item } \\
\hline Gram & + & + & + & + \\
\hline Aerobic growth & - & - & - & - \\
\hline Meat digestion & + & + & - & + \\
\hline Lipase & + & + & + & + \\
\hline Lecithinase & $-(9 / 11)^{*}$ & - & + & + \\
\hline Motility & + & + & + & + \\
\hline Hemolysis & $+(10 / 11)$ & + & + & + \\
\hline \multicolumn{5}{|l|}{ Acid from: } \\
\hline glucose & + & + & + & + \\
\hline maltose & $+(10 / 11)$ & + & + & + \\
\hline lactose & - & - & - & - \\
\hline sucrose & - & - & - & - \\
\hline salicin & - & - & - & + \\
\hline mannitol & - & - & - & - \\
\hline glycerol & $-(10 / 11)$ & - & + & - \\
\hline sorbitol & - & + & - & - \\
\hline trehalose & + & + & - & + \\
\hline fructose & $-(9 / 11)$ & - & - & + \\
\hline Nitrate reduction & - & - & - & - \\
\hline Growth on CBI agar & + & + & - & + \\
\hline Spore & ST & $\mathrm{ST}$ & $\mathrm{ST}$ & $\mathrm{ST}$ \\
\hline
\end{tabular}

*Isolates showing the property/Number tested. ST: Subterminal. 
the inoculum size. Only heat-treated tubes gave positive results with sample No. 16 and only diluted samples with No. 18. Samples Nos. 1 and 3 gave positive results only after twice or three-times repeated tests. Among the 80 samples collected in 1988, type C spores were detected from samples Nos. 20 and 21 only after centrifugation in the presence of $\mathrm{CaCO}_{3}$. All four tubes gave positive results with two samples, both of which were clover nectar and Argentina origin. Sample No. 22 contained 36 to 60 type F spores/g and No. 23 four type A spores/g. It was not difficult to isolate type A organisms from the 11 type A-positive samples, whereas type $\mathrm{C}$ organisms were isolated from only three of the 10 type-C-positive samples.

\section{Some Properties of the Isolates}

As Table IV shows, all type A, B, and F isolates belonged to group I (14). The type A isolate from sample No. 6 was atypical, possessing a high lecithinase and no hemolytic activity and fermenting glycerol. All the other isolates did not differ from the authentic strains of the respective types.

Table V. Detection of $C$. botulinum in honey to which spores were added

\begin{tabular}{cccccc}
\hline $\begin{array}{c}\text { Number of } \\
\text { spores added } \\
\text { to } 20 \mathrm{~g} \text { of } \\
\text { honey }\end{array}$ & $\begin{array}{c}\text { Spore susp. } \\
(1 \mathrm{ml})\end{array}$ & \multicolumn{2}{c}{$9 \mathrm{~g}$} \\
$\begin{array}{c}\text { Positives/ } \\
\text { test tubes }\end{array}$ & Heated & Unheated & Heated & Unheated \\
\cline { 3 - 6 } 100 & $3 / 3$ & $2 / 2^{*}$ & $2 / 2$ & $2 / 2$ & $2 / 2$ \\
& & $2 / 2^{* *}$ & $2 / 2$ & $2 / 2$ & $2 / 2$ \\
10 & $3 / 3$ & $1 / 2$ & $2 / 2$ & $0 / 2$ & $0 / 2$ \\
& & $2 / 2$ & $1 / 2$ & $0 / 2$ & $0 / 2$ \\
5 & $3 / 3$ & $1 / 2$ & $0 / 2$ & $0 / 2$ & $0 / 2$ \\
3 & $3 / 3$ & $1 / 2$ & $0 / 2$ & $0 / 2$ & $1 / 2$ \\
& & $0 / 2$ & $1 / 2$ & $0 / 2$ & $0 / 2$ \\
1 & $2 / 3$ & $0 / 2$ & $0 / 2$ & $0 / 2$ & $0 / 2$ \\
& & $0 / 2$ & $0 / 2$ & $0 / 2$ & $0 / 2$ \\
0.5 & $0 / 3$ & $1 / 2$ & $0 / 2$ & $0 / 2$ & $0 / 2$ \\
& & $0 / 2$ & $0 / 2$ & $0 / 2$ & $0 / 2$ \\
& & $0 / 2$ & $0 / 2$ & $0 / 2$ & $0 / 2$ \\
\hline
\end{tabular}

*Upper row: by the standard method; **Lower row: $\mathrm{CaCO}_{3}$ was added as a precipitation aid. 


\section{Evaluation of the Dilution-Centrifugation Method}

When 100 spores were added to $20 \mathrm{~g}$ of honey, all four tubes gave positive results; when 10 or fewer spores were added, the results were variable ('Table V). In some tests, the heat-treatment and/or addition of $\mathrm{CaCO}_{3}$ as a precipitation aid enhanced the detection, but not in other tests.

\section{DISCUSSION}

In 1986, a case of infant botulism, after feeding honey, was first diagnosed in Japan. The survey conducted by the study group organized by Ministry of Health and Welfare detected $C$. botulinum in $5.3 \%$ of 512 honey samples (11). The consumption of honey is increasing and Japan imports honey from many countries. Although the fatality rate of infant botulism is fortunately low, the patients would amplify and keep excreting $C$. botulinum in their feces, which would create a serious public health problem.

To further scrutinize the contamination of honey with $C$. botulinum spores, a long-term survey was conducted. There was no difference in the incidence of $C$. botulinum between domestic and imported honey. Type $\mathrm{C}$ and $\mathrm{E}$ spores have often been detected in soil of this country (15), but type A and B spores have seldom been detected. It was, therefore, expected before conducting the survey that type A or B spores would seldom be detected, at least in domestic honey. However, type A spores were detected in domestic honey samples. This may indicate some other route of contamination of honey than from soil via nectar.

Most surveys of honey for $C$. botulinum have been conducted in USA. Chin et al. (16) detected $C$. botulinum in 9 of 90 honey smaples. Most positive samples were those having been fed to the patients; only one sample was positive out of 63 samples not associated with infant botulism. Midura et al. (8) obtained an incidence of $10 \%$ among honey samples including those associated with cases. Sugiyama et al. (7) examined 241 samples of honey not associated with cases and detected C. botulinum in 18 samples (7.5\%). The organisms detected in honey have exclusively been types $\mathrm{A}$ and $\mathrm{B}$. Type $\mathrm{C}$ and $\mathrm{F}$ organisms were detected in honey in the present investigation. 
Although only a limited number of samples were tested, the incidence was low among the samples from Europe. Hauschild et al. (17) stated that $C$. botulinum distributed in Europe is mainly of nonproteolytic type B, whose spores may have been killed by the heat-treatment for detection. In the present survey, honey samples from USA were all negative, while type A spores were detected in samples of Hungarian and Spanish honey.

As for Chinese honey, Mitamura et al. (18) have detected type E spores and Huhtanen et al. (19) type B spores. In the present survey, nine (11.8\%) were positive among 76 Chinese honey samples and types A, B and $\mathrm{C}$ were detected in these positive samples. Although Yamakawa et al. (20) reported a dense distribution of type A and B spores in north-west China, Shinkiang district, Chinese honey is produced mostly in the south. It seems necessary to clarify whether contamination is from soil or some other sources. Japan imports a largest amount of honey from China and therefore attention should be paid to Chinese honey.

Type A and F sproes were detected in Argentina honey. Distribution of type $\mathrm{A}$ and $\mathrm{F}$ sproes in Argentina soil has been reported $(21,22)$. Since the nectar source was clovers, contamination of honey from soil via nectar can not be ruled out.

The incidence of C. botulinum was higher in the samples taken from drums or apiary than marketing honey. Sugiyama et al. (7) also reported a higher incidence in samples taken from apiaries than from shops. We added type A and $\mathrm{B}$ spores to honey in $104 / \mathrm{ml}$ and then kept at $25 \mathrm{C}$. After one year, the viable count of the spores decreased to less than $1 \%$ and the heat stability also decreased (23). From these results, it seems possible that some processes during purification and prolonged storage contributed to the lower incidences in marketing honey.

Several methods for testing honey for C. botulinum have been reported. Sugiyama et al. (7) reproted the dilution-dialysis method, but it requires a large amount of medium and skillful techiniques for use of dialysis tubing. Hauschild et al. (24) recommended the use of membrane filter, but our preliminary tests showed that it took fairly a long period for filtration of $20 \mathrm{~g}$ of honey. Amylase treatment accelerated filtration to a certain extent, but the technique is not so simple to treat many samples at a time. In contrast, the dilution-centrifugation method of Midura et al. (8) we used was simple and practicable. The recovery of the spores, however, should be improved, since Huhtanen et al. (19) reported that the samples giving positive results by the direct plating method gave negative 
results by the dilution-centrifugation method. The recovery of spores by the method was increased from $20-40 \%$ to $40-50 \%$ when $\mathrm{CaCO}_{3}$ was used as a precipitation aid (data not shown). Midura et al. (8) stated that the presence of seven to nine spores per $g$ of honey was needed for detection. The present results show that spore concentrations higher than one per gram always gave positive results (Table V). It appeared that the heat treatment sometimes accelerated detection, but sometimes detection was positive only with unheated cultures. In case of soil samples that usually contain a large number of contaminants, dilution of the sample is often effective for detection of $C$. botulinum. Honey does not contain such many contaminants that dilution would not be so effective as for soil samples. With one sample (No. 18), a positive culture was obtained only when diluted (Table III). It was rare that both heated and unheated cultures gave positive results. It seems that such unstable results do not reflect the effect of heat treatment, but low population or uneven distribution of the spores in honey. It seemed justified to recommend the use of at least four tubes of enrichment medium for detection of $C$. botulinum in honey. As with samples Nos. 1 and 3, the first test gave negative results and the twice or three-times repeated tests gave positive results. From the foregoing facts, it is presumed that such honey containing only a few spores may have given negative results.

Quantitative determinations of spores were made for the two samples that gave four positive cultures; the other samples may have contained spores in one per gram or lower concentrations. Sugiyama et al. (7) reported that the highest concentration of spores in honey not associated with infant botulism cases was $7 / 25$ g. Midura et al. (8) reported that honey fed to patients of infant botulism contained 5 to 15 spores/g and some contained as many as 70-80/g. In the present investigation, two samples from Argentina contained spores compatible to these figures. It is unbelievable that such heavy contamination occurred from the environment. The question if $C$. botulinum would proliferate in honey before ripening has remained to be solved. As reported by Dezfulian et al. (25), the isolates from honey did not differ from the authentic strains of the respective types in the biochemical or physiological characters, but further characterization seems necessary in connection with the behavior of $C$. botulinum in honey. 


\section{REFERENCES}

1. Pickett, J., Berg, B., Chaplin, E. and Shafer, M. B. (1976): Syndrome of botulism in infancy: clinical and electrophysiologic study. New Engl. J. Med., 295, 770-772.

2. Midura, 'T. F. and Arnon, S. S. (1976): Infant botulism: identification of Clostridium botulinum and its toxin in feces. Lancet, 2, 934-936.

3. Arnon, S. S. (1980): Infant botulsim. Ann. Rev. Med., 31, 541-560.

4. Sakaguchi, G. (1988): Honey and botulism. Jpn. J. Food Microbiol., 5, 3-9 (in Japanese).

5. Hall, J. D., McCroskey, L. M., Pincomb, B. J. and Hatheway, C. L. (1985): Isolation of an organism resembling Clostridium barati which produces type $\mathrm{F}$ botulinal toxin from an infant with botulism. J. Clin. Microbiol., 21, 654655.

6. McCroskey, L. M., Hatheway, C. L., Fenicia, L., Pasolini, B. and Aureli, P. (1986): Characterization of an organism that produces type E botulinal toxin but which resembles Clostridium butyricum from the feces of an infant with type E botulism. J. Clin. Microbiol., 23, 201-202.

7. Sugiyama, H., Mills, D. C. and Kuo, L-J. C. (1978): Number of Clostridium botulinum spores in honey. J. Food Prot., 41, 848-850.

8. Midura, T. F., Snowden, S., Wood, R. M. and Arnon, S. S. (1979): Isolation of Clostridium botulinum from honey. J. Clin. Microbiol., 9, 282-283.

9. Kautter, D. A., Lilly, T. Jr., Solomon, H. M. and Lynt, R. K. (1982): Clostridium botulinum spores in infant foods; a survey. J. Food Prot., 45, 1028-1029.

10. Noda, H., Sugita, K., Koike, A., Nasu, T., Takahashi, M., Shimizu, T., Ooi, K. and Sakaguchi, G. (1988): Infant botulism in Asia. Amer. J. Dis. Child., 142, 125-126.

11. Sakaguchi, G. (1987): Surveillance of honey for Clostridium botulinum. Rep. Minist. Hlth. Welfare (in Japanese).

12. Dezfulian, M., McCroskey, L. M., Hatheway, C. L. and Dowell, V. R. Jr. (1981): Selective medium for isolation of Clostridium botulinum from human feces. J. Clin. Microbiol., 13, 526-531.

13. Takayama, K., Nakano, H. and Hashimoto, H. (1990): Application of HGMF-ELISA for detection of Clostridium botulinum. Jpn. J. Bacteriol., 45, 609-610 (in Japanese).

14. Smith, L. D. S. (1977): The organism, its toxin, the disease. Charles C. Thomas, Springfield, Ill. 236p.

15. Karashimada, T. (1981): Epidemiological characteristics of human botulism occurred in Japan and their background. Rep. Hokkaido Inst. Publ. Hlth., 31, 1-5.

16. Chin, J., Arnon, S. S. and Midura, T. F. (1979): Food and environmental aspects of infant botulism in California. Rev. Infect. Dis., 1, 693-696. 
17. Hauschild, A. H. W., Hilsheimer, R., Weiss, K. F. and Burke, R. B. (1988): Clostridium botulinum in honey, syrups and dry infant cereals. J. Food Prot., 51, 892-894.

18. Mitamura, H., Kameyama, K. and Ando, Y. (1979): The contamination of spore-forming bacteria in honey. Rep. Hokkaido Inst. Publ. HIth, 29, 16-19 (in Japanese).

19. Huhtanen, C. N., Knox, D. and Shimanuki, H. (1981): Incidence and origin of Clostridium botulinum sproes in honey. J. Food Prot., 44, 812-814.

20. Yamakawa, K., Kamiya, S., Nishida, S., Yoshimura, K., Yu, Y., Lu, D. and Nakamura, S. (1988): Distribution of Clostridium botulinum in Japan and Shinkiang district of China. Microbiol. Immunol., 32, 579-587.

21. Ciccarelli, A. S. and Gimenez, D. F. (1981): p.291-301. In G. E. Lewis (ed.), Biomedical aspects of botulism, Academic Press, New York.

22. Gimenez, D. F. and Ciccarelli, A. S. (1968): Clostridium botulinum type F in the soil of Argentina. Appl. Microbiol., 16, 732-734.

23. Nakano, H., Okabe, T., Hashimoto, H., Yoshikuni, Y. and Sakaguchi, G. (1989): Changes in the population of Clostridium botulinum spores in honey during a long-term storage and mild heating. Jpn. J. Food Microbiol., 6, 97101 (in Japanese).

24. Hauschild, A. H. W. and Hilsheimer, R. (1983): Detection of Clostridium botulinum in honey by a procedure involving membrane filtration. Can. Inst. Food Sci. Technol. J., 16, 256-258.

25. Dezfulian, M. and Dowell, V. R. Jr. (1980): Cultural and physiological characteristics and antimicrobial susceptibility of Clostridium botulinum isolated from food-borne and infant botulism cases. J. Clin. Microbiol., 11, 604-609. 